\title{
Análise discursiva da estrutura correlativa "não -x, mas sim -y" e seu valor argumentativo em textos do gênero meme
}

\author{
Discursive analysis of the correlative structure "not -x, but rather -y" \\ and its argumentative value in texts of the meme genre
}

\author{
Daniele Cristina Campos ${ }^{1}$ \\ Maria Aparecida Lino Pauliukonis ${ }^{2}$
}

\begin{abstract}
Resumo: Este trabalho tem por objetivo analisar discursivamente a estrutura correlativa "não -x, mas sim -y" e o seu valor argumentativo sob a ótica da Teoria Semiolinguística, de Patrick Charaudeau (2008), em textos do gênero meme. Como pressupostos teórico-metodológicos basilares para análise, elegemos alguns dos conceitos-chave da Teoria Semiolinguística como contrato de comunicação, ato de linguagem, modos de organização do discurso enunciativo e argumentativo, bem como conceitos da Teoria da Argumentação e da Teoria da Correlação. Esse aporte teórico nos conduziu à compreensão de que discursos estruturados por "não -x, mas sim -y" são atravessados por duas vozes gerais. Essas duas vozes apresentam crenças ou valores sociais e, numa relação de força argumentativa, elas buscam refutar uma primeira voz geral (mais fraca) e introduzir uma segunda voz geral com o objetivo de marcar outro posicionamento com um argumento mais forte e mais importante.
\end{abstract}

Palavras-chave: Semiolinguística. Polifonia. Correlação. Gêneros textuais.

\begin{abstract}
This work aims to discursively analyze the correlative structure "not -x, but rather y" and its argumentative value from the perspective of Patrick Charaudeau's Semiolinguistic Theory (2008), in texts of the meme genre. As basic theoretical-methodological assumptions for analysis, we chose some of the key concepts of the Semiolinguistic Theory as a communication contract, act of language, ways of organizing the enunciative and argumentative discourse, as well as concepts from the Theory of Argumentation and the Theory of Correlation. This theoretical contribution led us to the understanding that speeches structured by "not $-x$, but rather $-y$ " are crossed by two general voices. These two voices present social beliefs or values and, in a relationship of argumentative strength, they seek to refute a first general voice (weaker) and introduce a second general voice in order to mark another position with a stronger and more important argument.
\end{abstract}

Keywords: Semiolinguistics. Polyphony. Correlation. Textual genres.

\footnotetext{
${ }^{1}$ Universidade Federal do Rio de Janeiro, Programa de Pós-Graduação em Letras, Rio de Janeiro, RJ, Brasil. Endereço eletrônico: danielecampos@id.uff.br.

${ }^{2}$ Universidade Federal do Rio de Janeiro, Faculdade de Letras, Programa de Pós-Graduação em Letras, Rio de Janeiro, RJ, Brasil. Endereço eletrônico: aparecidalino@gmail.com.
} 


\section{Introdução}

No âmbito de estudos do período composto, é de conhecimento geral que o processo sintático da correlação "sempre andou confundido com o da subordinação em todas as gramáticas brasileiras ou estrangeiras" (OITICICA, 1952, p. 13). No português brasileiro, a tradição gramatical, desde a Nomenclatura Gramatical Brasileira, publicada em 1959, reconhece apenas a coordenação e a subordinação como processos de articulação de cláusulas pertencentes ao período composto. Por conta disso, quando as gramáticas de viés tradicional fazem menção à correlação, geralmente, preferem incluí-la no rol de subtipos da coordenação ou da subordinação. Ademais, diante de estruturas correlativas, a tradição gramatical costuma fundamentar seus apontamentos teóricos em critérios formais de base morfossintática. Sendo assim, Pauliukonis (1995; 2001a) propõe que, ao se resgatar a "floresta inexplorada" da Teoria da Correlação (OITICICA, 1952, p. 2), devemos incorporar à análise das estruturas correlativas não apenas os componentes sintático-semânticos, mas também os componentes discursivo-pragmáticos.

Por correlação, considera-se "uma construção sintática de duas partes relacionadas entre si, de tal sorte que a enunciação de uma, dita prótase, prepara a enunciação de outra, dita apódose" (CAMARA JUNIOR, 1981, p. 87). Além disso, Rodrigues (2014) postula que o processo da correlação se constitui numa relação de interdependência, sendo esta, a principal característica definidora das estruturas correlativas.

Os oponentes da Teoria da Correlação, porém, não vislumbraram o que Oiticica preconizava: ao dizer que estruturas sintáticas diversas veiculam conteúdos semânticos diferentes, ele defendia que a forma peculiar das cláusulas correlatas, ou o seu modo de enunciação é responsável pelo conteúdo pretendido. Nesse sentido, pode-se utilizar uma estruturação correlata com fins específicos para se obter certos efeitos de sentido. Sob esse enfoque, atualmente é possível situar o processo da Correlação dentro de uma ampla teoria geral do discurso, a qual prevê a possibilidade de se determinar a atuação do emissor no ato interativo de linguagem de que faz parte.

Em relação aos estudos discursivos dos atos de linguagem, a Teoria Semiolinguística, de Patrick Charaudeau (2008), insere o discurso numa problemática interativocomunicacional em que se busca compreender os diferentes efeitos de sentidos produzidos por sujeitos sociodiscursivos em suas práticas linguageiras. Em função disso, elegemos alguns de seus pressupostos como aporte teórico-metodológico a fim de buscarmos compreender os aspectos semiolinguísticos, que envolvem o uso de discursos estruturados sob o par correlativo "não $-\mathrm{x}$, mas sim $-\mathrm{y}$ ” e seus efeitos argumentativos. 
Ademais, por entendermos que as formas mais naturais e espontâneas de manifestação da linguagem encontram-se no uso real da língua, para a constituição do corpus, selecionamos para análise dois textos do gênero meme com o intuito de verificarmos valores argumentativos que envolvem o uso dessas estruturas correlativas.

No que toca aos textos do gênero meme, consideramo-lo na perspectiva bakhtiniana em que, ao nos comunicarmos, construímos modelos de comunicação relativamente estáveis, fruto de uma ação coletiva (cf. BAKHTIN, 1997). Dessa forma, como um gênero textual, acrescentamos ao estudo do meme a visão de que a ele "devemos atribuir um valor pragmático, pois os procedimentos que o configuram objetivam tornar o usuário apto a converter o sentido em alguma forma de ação" (MARI, 2004, p. 66). Isso porque, segundo Souza (2013), os memes têm por objetivo não só veicular conteúdo, mas também transmitir conhecimentos de indivíduo para indivíduo, replicando discursos vigentes em ambientes virtuais por questões de filiação e adesão aos sentidos, construídos através do conteúdo neles expresso.

Em termos de organização, estruturamos este trabalho da seguinte forma: de início, empreendemos uma revisão de literatura acerca da Teoria Semiolinguística, de Patrick Charaudeau e investigamos a maneira pela qual a linguagem passa a ser compreendida neste campo do saber por uma relação forma/sentido. Além disso, recortamos alguns dos seus conceitos-chave, como contrato de comunicação, ato interativo de linguagem e modos de organização do discurso, com foco no enunciativo e no argumentativo. Na sequência, resgatamos a "floresta inexplorada", de Oiticica, sob a perspectiva de sua análise como um recurso semântico-argumentativo. Em seguida, a partir do exposto, procedermos à descrição e análise do corpus, constituído por dois textos do gênero meme. Por fim, tecemos as conclusões e indicamos as obras consultadas.

\section{Os termos "semio" + "linguística" e a concepção de linguagem}

Para Charaudeau (2007) a linguagem pode ser concebida como multidimensional. Isso implica dizer que ela comporta diversas dimensões como a cognitiva, a psicossocial, a semiótica, dentre outras. Nessa perspectiva, o autor propõe que os fenômenos da linguagem sejam tratados sob uma ótica transdisciplinar na qual privilegia tanto os aspectos da forma linguística quanto os aspectos ligados à construção dos sentidos. Nesse contexto, insere-se a proposta "semiolinguística" cuja segmentação do termo, nas palavras do autor, refere-se à 
[...] semio-, de "semiosis", evocando o fato de que a construção de sentido e sua configuração se fazem através de uma relação forma-sentido (em diferentes sistemas semiológicos), sob a responsabilidade de um sujeito intencional, com um projeto de influência social, num determinado quadro de ação; linguística para destacar que a matéria principal da forma em questão - a das línguas naturais. Estas, por sua dupla articulação, pela particularidade combinatória de suas unidades (sintagmático-paradigmático em vários níveis: palavra, frase, texto), impõem um procedimento de semiotização do mundo diferente das outras linguagens. (CHARAUDEAU, 2007, p. 13, grifo do autor)

Assim, para a teoria semiolinguística, a linguagem não é vista como uma unidade autônoma de sentido, como se fosse um objeto transparente o qual veicula, por si mesmo, sentidos já pré-existentes. Pelo contrário, ela passa então a ser concebida como um objeto não transparente tendo em vista que o "mundo não é dado a princípio. Ele se faz através da estratégia humana de significação" (CHARAUDEAU, 2008, p. 21, grifo do autor). Daí ser preciso um ponto de vista que privilegie a dupla dimensão da linguagem: a semiótica e a linguística.

Isso posto, é justamente essa perspectiva que abre caminho para analisarmos os discursos estruturados sob o par correlativo "não -x, mas sim -y" e o seu valor argumentativo em textos do gênero meme.

A partir do viés semiolinguístico, Charaudeau (2007) propõe que as línguas naturais são articuladas num duplo processo denominado "semiotização" ou "discursivização" do mundo, que corresponde à transformação e à transação.

Durante o processo de transformação os objetos semióticos, sob influência social do sujeito falante, passam de um "mundo a significar" a um "mundo significado". No processo de transação, o "mundo significado" torna-se objeto de troca entre dois sujeitos: o sujeito falante que assume a posição de enunciador desse ato e o outro sujeito que se coloca no papel de destinatário e também interpretante desse objeto.

Para se compreender melhor esses dois fenômenos de "semiotização" do mundo, o autor expõe que o processo de transformação se desdobra em, pelo menos, quatro tipos de operações linguístico-discursivas (identificação, qualificação, ação e causação). No que diz respeito ao processo de transação ou expressão textual, para Charaudeau (2007), tal processo é realizado de acordo com quatro princípios (alteridade, pertinência, influência e regulação).

Nesse contexto, vale ressaltar que a estrutura correlativa "não -x, mas sim -y" enquadra-se no processo de causação, na medida em que os elementos estão estruturados sob uma ótica lógica dos argumentos de "causa e efeito". 
No que se refere aos quatro desdobramentos do processo de transformação, temos a identificação de seres materiais, reais ou imaginários, os quais se transformam em “identidades nominais” por meio do processo de nomeação. A apreensão das propriedades e características desses seres, caracterizando-os e transformando-os em "identidades descritivas", ocorre no processo de qualificação. Por sua vez, através do processo de ação, os seres do mundo são transformados em "identidades narrativas”, devido à indicação da ação que esses seres agem ou sofrem. Por fim, no processo de causação, são explicitadas as razões pelas quais esses seres agem ou sofrem a ação.

Em complementação a esses quatro processos de transformação, há quatro princípios inerentes ao processo de transação, a saber: a) o princípio de alteridade que insere todo ato de linguagem em um fenômeno de troca entre dois sujeitos os quais firmam um contrato comunicacional e se reconhecem mutuamente como sujeitos semelhantes e diferentes; b) o princípio de influência que visa afetar emocionalmente o sujeito destinatário do contrato comunicacional, compelindo-o a agir de uma determinada maneira; c) o princípio de regulação se conecta ao princípio da influência à medida que os parceiros do ato de troca comunicacional tomam ciência do ato de linguagem do qual participam ${ }^{3}$; d) o princípio de pertinência exige que o ato de linguagem seja adequado ao contexto e à finalidade contratual, posto que se pressupõe que os parceiros desse ato de troca compartilham saberes sobre o mundo, sobre valores sociais, sobre comportamentos etc.

Por fim, esses dois processos de semiotização do mundo permitem-nos inferir que a linguagem verbal humana não representa a tradução de um mundo "real", mas a encenação desse mundo que é "representado" por meio de um "ato de linguagem" no qual sujeitos falantes estabelecem um pacto contratual regulado pela ação e influência sobre o que se deseja crer/informar como verdade.

Dessa forma, é nesse jogo de representações de mundo por diferentes sujeitos que estamos considerando os discursos estruturados sob o par correlativo "não -x, mas sim -y". $\mathrm{O}$ valor argumentativo dessa estrutura se manifesta na medida em que, primeiro, nega-se um argumento importante que pertence a uma "voz ou crença geral" para, em seguida, introduzir outro argumento que se impõe como uma segunda voz, mais forte e mais convincente, conforme expomos, de modo mais detalhado, na análise do corpus.

\footnotetext{
${ }^{3}$ Cabe ressaltar que isso permite que se chegue ao contrato comunicativo, pois os parceiros do ato linguageiro devem regular seus discursos de modo recíproco num jogo de influências.
} 


\section{A mise-en-scène do ato de linguagem e o contrato de comunicação}

$\mathrm{O}$ ato de linguagem, na perspectiva da semiolinguística, é visto como um encontro dialético entre sujeitos falantes, os quais se tornam parceiros de troca que se processa por meio de um contrato comunicacional. Dessa maneira, o ato de linguagem pressupõe que ambos os parceiros de troca compartilhem o mínimo de saberes postos em cena no jogo de troca linguageira. Com efeito, o ato de linguagem abrange dois espaços: um espaço de restrições e um espaço de estratégias. O primeiro "compreende as condições mínimas as quais é necessário atender para que o ato de linguagem seja válido". O segundo, "corresponde às escolhas possíveis à disposição dos sujeitos na mise-en-scène do ato de linguagem" (CHARAUDEAU, 2007, p. 17).

As restrições e as estratégias presentes no ato de linguagem manifestam-se por meio de um contrato comunicacional. Charaudeau (2008) esclarece que a noção de contrato pressupõe que os parceiros de troca pertençam a um mesmo corpo de práticas sociais e, dessa forma, devam aceitar as mesmas representações linguageiras provenientes dessas práticas sociais. Ademais, o autor acrescenta que todo ato de linguagem resulta de um jogo de estratégias discursivas que nascem em circunstancias específicas e que se realiza no ponto de encontro dos processos de produção e de interpretação. Esse ponto de encontro, por seu turno, é encenado por duas entidades que se desdobram em quatro sujeitos assimétricos e não em dois sujeitos simétricos (emissor e receptor).

A seguir, apresentamos o quadro de representação proposto pelo autor com o fito de demonstrar didaticamente como ocorre o ato de linguagem e os sujeitos que dele participam.

Figura 1 - Esquema de representação do ato de linguagem

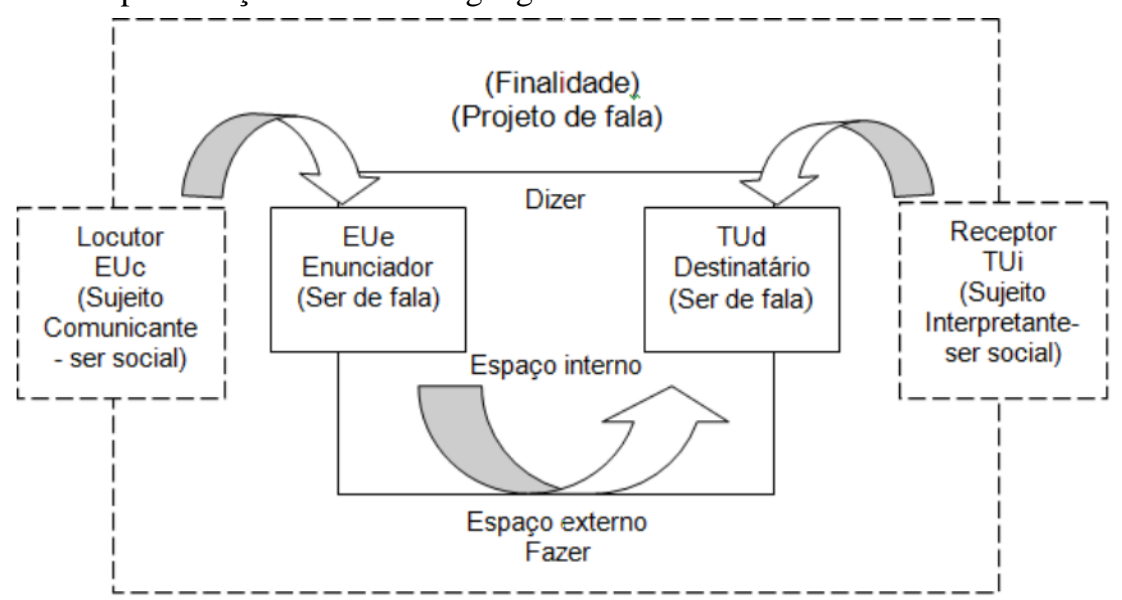

Fonte: quadro adaptado de Charaudeau (2008, p. 52). 
O quadro, de Charaudeau (2008), demonstra-nos que o ato de linguagem se desdobra em dois circuitos os quais se realizam em dois espaços: um interno e um externo. No espaço interno, ocorre o "circuito da fala configurada", ou seja, corresponde ao espaço destinado à fala encenada a qual é planejada, vigiada e controlada nos moldes de um contrato de comunicação. Dentro desse circuito interno, instalam-se dois seres de fala (EUe e TUd), os quais assumem o papel de protagonistas do ato de linguagem.

Ao circuito externo, pertencem dois parceiros, reconhecidos como seres sociais, o EUc (comunicante) e o TUI (interpretante), cuja atuação dá-se a partir das representações linguageiras oriundas das práticas sociais partilhadas. No instante interpretativo, o TUi, ao reconstruir a representação do TUd, pode aceitar ou rejeitar as investidas que o EUc lança sobre o TUd.

Com efeito, a partir dessa perspectiva, podemos depreender que é por meio do desdobramento dessas quatro entidades representadas acima que se deflagra o processo interpretativo. Daí Charaudeau (2008) afirmar que todo ato de linguagem se instaura numa arena de aventuras na qual encontramos apostas e expectativas. Isso quer dizer que os atores envolvidos no ato de linguagem farão uso de manobras e estratégias discursivas a fim de encenarem suas intenções comunicativas.

Dito isso, concluímos que o ato de linguagem não esgota sua significação em si mesmo, haja vista que a linguagem é, ao mesmo tempo, um objeto não autônomo e não transparente. Os sujeitos participantes do ato de troca linguageira criam hipóteses, constroem estratégias, antecipam possíveis interpretações, regulam contratos comunicacionais e estabelecem, por meio dele, lugares a serem ocupados no momento da interação verbal. Portanto, podemos reiterar que a linguagem é, de fato, um fenômeno multidimensional e pode, sim, ser estudada numa perspectiva transdisciplinar.

À vista disso, sabendo que a correlação é um processo bastante produtivo em textos de tipologia argumentativa, como demonstrou Módolo (2005), a seguir, discutiremos um dos conceitos importantes da Teoria Semiolinguística, de Patrick Charaudeau, fundamentais para o exame da estrutura correlativa analisada nos memes.

\section{Os modos de organização do discurso}

Conforme sua função e finalidade, o discurso pode ser ordenado e agrupado em quatro distintos modos de organização: o Enunciativo, o Descritivo, o Narrativo e o Argumentativo. Cada um desses modos discursivos confere, ao mesmo tempo, uma organização do "mundo referencial" e uma organização da "encenação" desse mundo construído, apresentado em 
uma lógica de construção descritiva, narrativa e/ou argumentativa. Todas essas três lógicas de construção são afetadas pelo modo de organização enunciativo, de modo que ele orienta a maneira pela qual o sujeito falante age na encenação do ato de linguagem (CHARAUDEAU, 2008), ou seja, o enunciativo participa também da organização dos outros modos.

Durante o ato de encenação da linguagem, o locutor vale-se de estratégias discursivas para encenar seu dizer com a finalidade de produzir determinados efeitos de sentido sobre o interlocutor. Assim, se o locutor tem por finalidade demonstrar seu ponto de vista acerca dos fatos do mundo com o objetivo de afetar o comportamento do interlocutor, o modo de organização será ao enunciativo prioritariamente. Se sua finalidade residir em identificar e qualificar os seres e os processos do mundo, de forma mais objetiva ou não, o modo de organização corresponderá ao descritivo.

Por outro lado, se seu objetivo for construir uma sucessão temporal das ações a fim de produzir um relato, o modo de organização será o narrativo. Por fim, se o locutor tiver por finalidade expor e provar as causas dos fatos do mundo com o fito de influenciar e persuadir o ponto de vista do interlocutor, o modo de organização será o argumentativo. Como já enunciado, em todos eles haverá traços enunciativos.

No âmbito desses quatro modos de organização do discurso, importa-nos aqui discorrer com mais detalhes, sobre os modos Enunciativo e Argumentativo, devido às especificidades do nosso objeto de análise que se insere em textos de tipologia argumentativa.

\section{Modo enunciativo}

Todo ato de linguagem é composto por um Propósito referencial o qual se encaixa num Ponto de vista enunciativo do sujeito falante, configurando assim uma Situação de Comunicação (CHARAUDEAU, 2008). Dentro dessa relação, é possível observarmos o comportamento enunciativo dos protagonistas do ato de encenação da linguagem. Em decorrência disso, a relação de influência que o EUe exerce sobre o TUd pode ser explicitada por três comportamentos discursivos diferentes, a saber: comportamento alocutivo, comportamento elocutivo e comportamento delocutivo.

No comportamento alocutivo, o EUe marca sua posição, numa relação de influência, e impõe ao TUd um determinado comportamento. Além disso, independente da identidade psicossocial e do comportamento efetivo dos interlocutores, o sujeito falante (EUe), na instância de sua enunciação, atribui a si e ao TUd "papéis linguageiros" de superioridade ou de inferioridade. 
Dessa forma, EUe e TUd podem estabelecer uma relação de força ou uma relação de pedido, que se concretiza por meio da modalização de determinadas categorias da língua, como, por exemplo, interpelação, injunção, autorização, aviso, julgamento, sugestão, proposta, interrogação e petição (Cf. CHARAUDEAU, 2008, p. 85).

O comportamento elocutivo, por sua vez, tem como característica explicitar o ponto de vista do locutor (EUe) ou do interlocutor (TUi) sobre o mundo (propósito referencial). Neste caso, o que está em jogo não são as implicações de seu ponto de vista sobre o TUd, mas sim o comportamento subjetivo do EUe ou do TUi. Nessa perspectiva, é revelado o ponto de vista interno dessas duas entidades de fala. Dessa maneira, pode-se revelar um saber, avaliar, especificar motivações, demonstrar engajamento ou, ainda, uma tomada de decisão (cf. CHARAUDEAU, 2008, p. 83).

Por fim, no comportamento delocutivo, ocorre o apagamento do ponto de vista do EUe, o qual, numa relação com um discurso de terceiros, coloca-se como testemunha, não implicando, neste caso, reações no TUd. Com efeito, tem-se uma enunciação com aparência de objetividade. Nesse tipo de comportamento, é muito comum o uso de discursos relatados e asserções acerca de como o mundo existe e se impõe por si só (cf. CHARAUDEAU, 2008, p. $83)$.

\section{Modo argumentativo}

O modo de organização argumentativo representa uma mecânica discursiva que possibilita produzir argumentos sob diferentes pontos de vista. Todavia, tal modo de organização não se restringe ao âmbito das categorias da língua responsáveis por produzir diferentes manobras discursivas. Tais categorias representam as diferentes maneiras que o sujeito falante dispõe para modalizar seu discurso, atribuindo aos argumentos uma relação de força e influência.

O ato de argumentar, segundo Charaudeau (2008, p. 206), constitui "uma atividade discursiva que, do ponto de vista do sujeito argumentante, participa de uma dupla busca". A "primeira busca" é racional e almeja construir um ideal de verdade. A "segundo busca" tem por objetivo perseguir um ideal de persuasão. Nessa esteira, Charaudeau (2008, p. 2, grifo do autor) propõe que a argumentação se estabelece "numa relação triangular entre um sujeito argumentante, uma proposta sobre o mundo e um sujeito-alvo".

A título de sistematização, na página a seguir, vejamos a ilustração proposta pelo autor: 
Figura 2 - Esquema de representação da argumentação

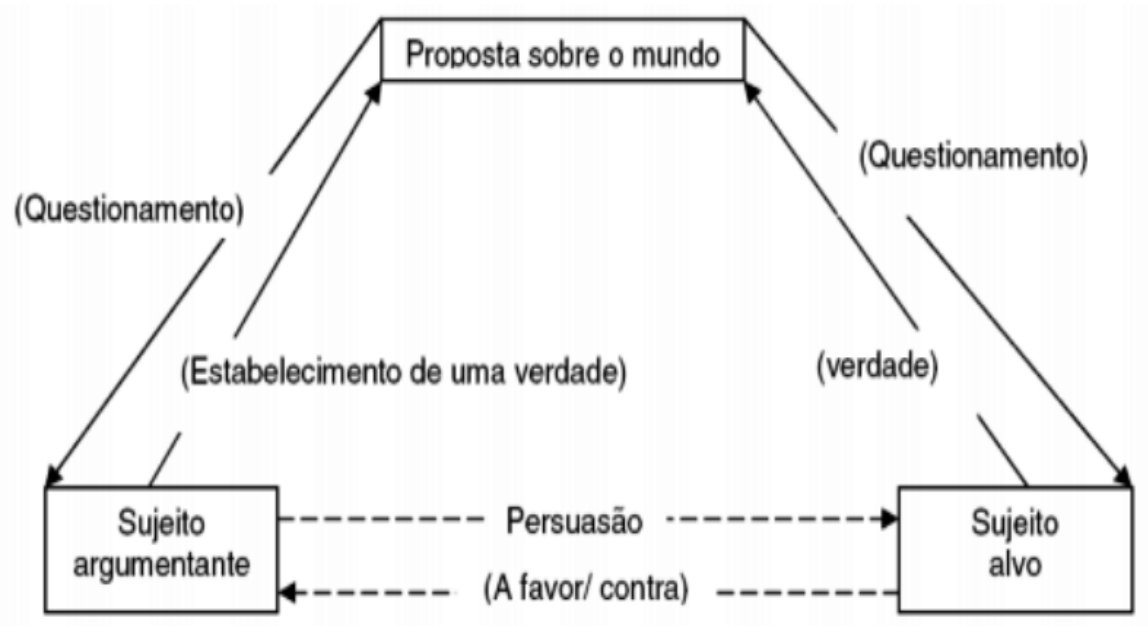

Fonte: Charaudeau (2008, p. 205).

Conforme se observa no esquema de representação da argumentação, no topo da pirâmide, encontra-se a "proposta sobre o mundo" cuja função é provocar um questionamento no outro acerca da legitimidade de uma determinada proposta. Na base da pirâmide, localizam-se dois sujeitos: um argumentante e um alvo. Ao primeiro, cumpre-lhe a responsabilidade do engajamento argumentativo, buscando desenvolver um raciocínio que estabeleça, sob um dado ponto de vista, uma verdade própria ou universal. No que tange ao segundo sujeito, ele se coloca como alvo do projeto argumentativo do sujeito anterior.

Nesse viés, como em um jogo de aposta, o sujeito argumentante, após sucessivas investidas argumentativas, espera influenciar o ponto de vista do sujeito alvo. Entretanto, nesse processo dialógico, o sujeito alvo pode aderir (ficar a favor) ou refutar (ficar contra) o ponto de vista do sujeito argumentante. Assim, o modo de organização argumentativo pode ser traduzido, da seguinte forma:

A uma visão dialética em que, a partir de um tema, o sujeito argumentador organiza uma tese -constituída de uma asserção ou de um conjunto de asserções, que dizem algo sobre o mundo - em função da qual o sujeito deve assumir uma posição contra ou a favor, ancorada em justificativas ou argumentos, corresponde o ponto de vista argumentativo. (PAULIUKONIS, 2001b, p. 95)

Desse modo, durante um tenso jogo de apostas, no processo da dialética argumentativa, entram em cena as categorias da língua responsáveis pela modalização (explícita ou implícita) do discurso argumentativo. Por se tratar de um jogo, em última 
instância, uma argumentação corre o risco de ser suplantada se não superar a contestação de argumentos contrários.

Dentro desse cenário, o uso discursivo do par correlativo "não -x, mas sim -y" auxilia no processo de defesa de uma tese proposta pelo enunciador. A argumentação estruturada por esse processo correlativo equaliza duas vozes contraditórias: uma que traduz a voz geral e outra que busca afirmar um argumento novo e mais forte. Demonstrando, portanto, um processo polifônico de um jogo entre duas vozes gerais.

\section{O estatuto semântico-argumentativo da correlação}

Neste trabalho, partimos da premissa de que a estrutura correlativa "não -x, mas sim y" possui, em sua formação, um estatuto sintático e um estatuto semântico-argumentativo. No que tange ao estatuto sintático, a correlação é constituída por conectores que vêm aos pares em uma relação de interdependência entre dois enunciados (RODRIGUES, 2014). Já no que se refere ao estatuto semântico-argumentativo, a relação de interdependência se dá pela enunciação de dois atos de fala em que o segundo termo é sempre evocado pela enunciação do primeiro termo (PAULIUKONIS, 2001a). Desse "nexo relacional" destaca-se a força argumentativa do enunciado polifônico.

Sob esse enfoque, de acordo com Pauliukonis (2001a, p. 122), a Teoria da Correlação pode ser estudada sob a ótica do "que hoje se entende como análise polifônica de dois atos de fala instituídos no mesmo enunciado". Isso se deve ao fato de a correlação, em seu bojo, apresentar duas vozes que se tencionam em torno de argumento(s) que se revela(m) durante a encenação do ato de linguagem.

Ducrot e Vogt (apud KOCH, 2011, p. 142, grifo nosso), defendem que "enunciados do tipo $X$ mas $Y$ permitem sempre uma descrição polifônica, em que se atribui $\mathrm{X}$ a um enunciador diferente do locutor". Ducrot (1988) salienta ainda que é no discurso que os enunciadores manifestam suas posições ideológicas por meio da enunciação. Isso é importante porque diferentes sujeitos, cujas vozes são atravessadas por outras vozes, entram em cena no processo de semiotização do mundo. Assim, ao se produzir um enunciado do tipo $X$ mas $Y$, o sentido do enunciado resultaria do confronto de, no mínimo, duas vozes gerais.

Em enunciados do tipo "Pedro não é inteligente, mas aplicado", a negação auxilia na refutação da primeira proposição, funcionando como uma voz de recusa a um discurso atribuído a outrem (cf. VOGT, 1980, p. 156). Isso ocorre porque o jogo de refutação "procede de um movimento argumentativo que consiste em demonstrar que uma tese é falsa" (CHARAUDEAU, 2008, p. 204). Neste caso, estamos diante de uma negação argumentativa 
na medida em que "um enunciado negativo é sempre, num certo nível, a encenação de um diálogo com um interlocutor imaginário. Dizendo não-B, o falante representa uma anunciação virtual de B e se opõe a esta enunciação" (VOGT, 1980, p. 112).

Ducrot e Vogt acrescentam que, em enunciados do tipo "Pedro não é inteligente, mas aplicado" (VOGT, 1980, p. 158, grifo nosso), o advérbio de negação forma com a conjunção "mas" o morfema descontínuo não...mas. Ao nosso ver, esse par descontínuo, do qual fala os autores, forma a estrutura correlativa "não -x, mas sim -y". Nesse processo correlativo, a partícula adverbial afirmativa funciona como um recurso de ênfase discursiva, cuja função é realçar o argumento mais importante.

Em síntese, um enunciado que contém uma "negação argumentativa" pode ser considerado uma pequena obra teatral na medida em que, ao se enunciar uma frase negativa, ao menos, duas vozes encenam um diálogo sobre dois pontos de vista distinto (DUCROT, 1988). Sendo assim, em enunciados negativos, normalmente marcado pelo advérbio "não", a negação funciona como uma recusa que auxilia ou reforça a refutação sobre o discurso de terceiros (VOGT, 1980).

Outrossim, nos estudos acerca do paradigma dos marcadores de oposição, a conjunção adversativa "mas" é considerada, por si só, um "operador argumentativo por excelência" (DUCROT apud KOCH, 2011, p. 104, grifo da autora). Nessa linha, Ducrot (2009) acrescenta que o morfema "mas" é capaz de colocar em cena argumentos que se orientam em direções opostas com uma manobra de grande poder persuasivo.

Dessa forma,

[...] a palavra mas é, entre outras coisas, especializada nessa função - eis por que, aliás, é destaque no discurso persuasivo. Graças a ela, podem-se assumir os argumentos contrários à conclusão que se visa. Basta fazer com que eles sejam seguidos por um mas, sem ter nem mesmo necessidade de refutá-los, manobra que não é muito cansativa, e que tem vantagens persuasivas eminentes. (DUCROT, 2009, p. 24, grifo nosso)

No movimento argumentativo da linguagem, consoante às afirmações de Ducrot, em enunciados com "mas", podemos inferir que o locutor evoca dois enunciadores. Nessa dinâmica, o primeiro enuncia um argumento que orienta a uma dada conclusão; já o segundo enuncia um argumento que orienta no sentido contrário à conclusão anterior.

Nesse viés, já que “a natureza deste jogo linguístico instituído pela conjunção mas é fundamentalmente dramática, 'teatral'” (VOGT, 1980, p. 159, grifo nosso), é lícito afirmar que o uso de "mas" está sempre condicionado a um tipo de encenação do discurso de outrem. 
Isso posto, a estrutura correlativa "não $-\mathrm{x}$, mas sim $-\mathrm{y}$ ", em seu estatuto interno, é formada por um processo semântico-argumentativo que acolhe enunciados polifônicos. Ademais, acrescenta-se que o operador argumentativo "mas", seguido de ênfase afirmativa, estabelece uma relação de interdependência com a contraparte negada. $\mathrm{O}$ enunciado introduzido pela negação refuta diretamente o discurso de seu interlocutor, conduzindo-lhe a uma tensão que se apresenta por meio de duas vozes gerais no jogo argumentativo da linguagem.

\section{Análise do corpus}

Tendo em vista que a Correlação pode ser estudada a partir de uma ampla teoria geral do discurso, buscamos, em textos do gênero meme, analisar a dinâmica argumentativa que se estrutura sob o par correlativo "não -x, mas sim -y". Sendo assim, selecionamos dois textos do gênero meme. $\mathrm{O}$ primeiro texto refere-se ao meme do Chapolin crente, (figura 3); o segundo, ao meme do Presidente Donald Trump, (figura 4). Esses dois memes circulam na internet sob domínio público e podem ser localizados por meio da ferramenta de busca do Google imagens.

Com base nos pressupostos teórico-metodológicos da Teoria Semiolinguística, partimos do princípio de que a estrutura correlativa "não -x, mas sim -y” equaliza argumentos que se tencionam entre duas vozes gerais. Em seu estatuto sintático, a correlação é estatuída por PRÓTASE (elemento negativo) e APÓDOSE (conjunção de valor adversativo, seguido de partícula de reforço afirmativo), formando, assim, o par correlativo "não -x, mas sim -y". Em seu estatuto semântico-argumentativo, esse par correlativo é constituído por um enunciado polifônico.

Na dinâmica argumentativa presente em "não -x, mas sim -y", primeiro, nega-se uma voz geral, que introduz "crenças" ou "valores", em seguida, acrescenta-se uma outra voz geral por meio da conjunção "mas". A contraparte, introduzida pelo "mas", contém um argumento mais forte e mais convincente, intensificado pela partícula de reforço afirmativo.

Dito isso, na página a seguir, apresentamos o exame do corpus. 
Figura 3 - Meme do Chapolin crente

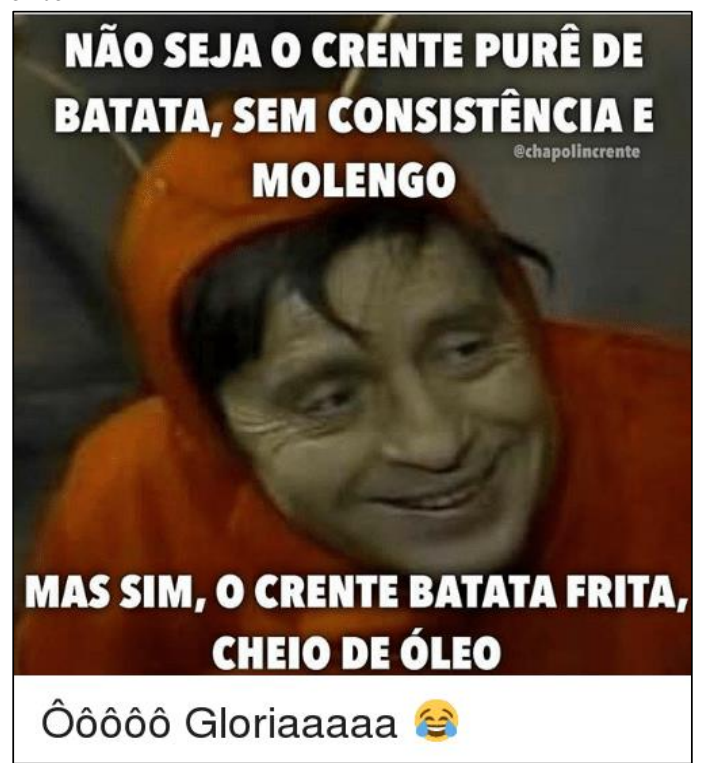

Fonte: Google imagens. Acesso em: 28 nov. 2019.

Na figura 3, temos o personagem Chapolin, o qual se tornou bastante conhecido pelo público em geral através do seriado mexicano "Chapolin colorado". Dentro desse seriado, esse personagem normalmente ironiza a sua fala e a fala de outros personagens, passando assim a ser conhecido como um ícone de discursos irônicos. Daí advém as pistas para o efeito de humor que o locutor planeja influir nos seus "hipotéticos" interlocutores ao selecionar a figura desse personagem como um fictício locutor que compartilha práticas religiosas. Com isso, o discurso religioso do personagem Chapolin, por ora "crente", passa a circular na internet, podendo ser localizado, dentre inúmeras páginas, sobre o domínio @ chapolincrente.

Nesse meme, observamos que, no processo de transformação do "mundo a significar" para um "mundo significado", entram em cena algumas construções metafóricas como "purê de batata" e "batata frita" que se relacionam com a qualificação de uma entidade material identificada como "crente". Dentro desse engenhoso processo, a entidade "crente" se torna alvo de duas declarações: a primeira que afirma que ele não deve ser aquele tipo de crente molengo, igual a um purê de batata e a segunda que afirma que ele deve ser um modelo de crente cheio de óleo igual à batata frita.

Para reconstruirmos essas duas metáforas, as quais atribuem valor à identidade do "crente", é preciso compreendermos o que representa a figura do "óleo" no discurso religioso.

Dentro do discurso religioso, o "óleo" representa a manifestação do espírito de Jesus. A isso, deve-se a interpretação da passagem bíblica localizada no evangelho de Mateus 25:113. Nessa passagem, dez virgens, as quais representam o corpo social da igreja, saem ao encontro do noivo, que representa Jesus. Cinco dessas virgens são consideradas insensatas, 
porquanto, ao saírem em busca do noivo, levam com elas apenas o candeeiro, esquecendo-se do óleo. Ou seja, elas são como aqueles crentes típicos "purê de batata" que apenas frequentam a igreja aos domingos, porém, em suas práticas semanais, não participam dos rituais religiosos, como orar, jejuar, subir monte, ler a palavra etc.

Do lado oposto, ao comportamento dessas cinco mulheres, estão as cinco virgens sensatas que, sempre vigilantes, carregam consigo não só seus candeeiros, mas também o óleo. Quando o noivo adentrou na igreja, apenas as virgens sensatas, que se encontravam com óleo em seus candeeiros, puderam ter com o noivo. Ou seja, aqueles crentes "batata frita", que não são preguiçosos, por praticarem fielmente os rituais que a religião lhes impõe, tornam-se, portanto, crentes ungidos, cheios do óleo do espírito de Jesus.

Dito isso, com base no significado do "óleo" e sua importância para o discurso religioso, podemos, então, na sequência, interpretar o enunciado "não seja o crente purê de batata, sem consistência e molengo - mas sim, o crente batata frita, cheio de óleo. Ôôôôô Gloriaaaaa".

No processo de transação de um mundo já significado, contido no enunciado do meme sob análise, encontramos entidades que protagonizam a encenação de um projeto de troca e influência linguageira. Dentro desse processo dialógico, aparecem duas vozes gerais, as quais passam a ser encenadas por dois sujeitos de fala que se desdobram em quatro entidades distintas, a saber: EUc que, ao instaurar o projeto de fala, encena um EUe e um EUd. Para que $o$ ato de fala se complete, ao fim, surge uma quarta entidade (TUi) que se instala no momento em que ocorre o processo de interpretação.

Com base na metáfora "purê de batata", podemos inferir que "aquele crente", que não ora, não jejua, não sobe monte e não se alimenta da palavra, é um crente "molengo" igual a um "purê". Nesse viés, a partir da declaração: "não seja o crente purê de batata, sem consistência e molengo", o EUe espera influenciar o comportamento do TUd, pela enunciação da primeira parte da estrutura correlativa, a qual impõe uma "negação argumentativa".

Em um segundo momento da encenação desse ato de fala, surge uma segunda voz geral instaurada na figura do TUi. Tal entidade representa um sujeito social que se move na arena teatral, valendo-se de um comportamento elocutivo. Nesse instante, TUi marca seu ponto de vista através de uma manobra discursiva que se materializa pelo uso do operador argumentativo "mas", acrescentando a esse operador uma partícula afirmativa cuja finalidade é intensificar o seu ponto de vista. Nesses termos, sob a forma da metáfora "crente batata frita", instaura-se, enfaticamente marcada pela correlação entre as cláusulas, a segunda declaração do TUi: "mas sim, o crente batata frita, cheio de óleo - Ôôôô Gloriaaaaa". 
Por todo o exposto, podemos afirmar que as metáforas "purê de batata" e "batata frita" são utilizadas pelos protagonistas que encenam o ato de linguagem como dois argumentos acerca do tema "práticas religiosas". Com efeito, esses dois argumentos funcionam como verdadeiros provérbios, já que uma de suas características gerais é que o enunciador não fala em seu nome, mas em nome de toda uma comunidade, por meio de declarações que constituem "doxas", ou verdades aceitas. Isso é importante na medida em que se evidencia que os discursos instanciados sob a forma da estrutura correlativa "não $-x$, mas sim $-y$ " se encaixam também no esquema triangular da argumentação proposto por Charaudeau (2008).

Dessa forma, concluímos que a estrutura correlativa "não -x, mas sim -y" é um recurso semântico-argumentativo, cuja estrutura permite construir uma proposta sobre o mundo, um argumento e um contra-argumento que se tensionam num processo dialógico entre duas vozes gerais.

Dito isso, com base nos aspectos semiolinguísticos, estruturados sob a correlação "não $-\mathrm{x}$, mas sim -y", podemos analisar a figura 04.

Figura 4 - Meme do Presidente Donald Trump

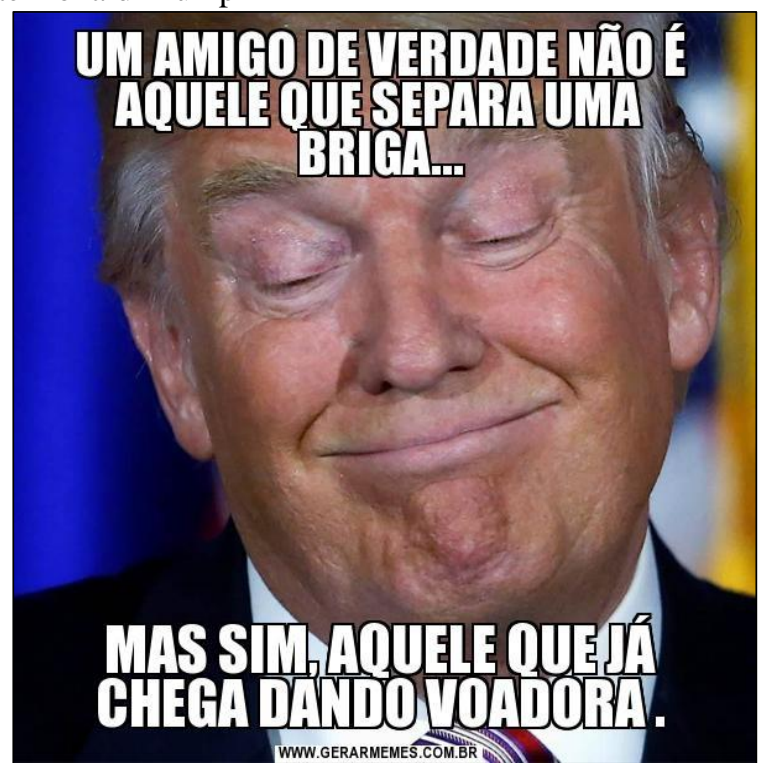

Fonte: Google imagens. Acesso em: 28 nov. 2019.

Na figura 4, temos a imagem do Presidente dos Estados Unidos, Donald Trump, atrelada a um enunciado que remete a um discurso sobre amizade. Socialmente, circula a ideia de que o presidente Trump é do tipo radical, do qual não mede esforços para entrar em uma briga. Por conseguinte, devido a esse estilo "brigão", Trump colecionaria poucas amizades. Nessa perspectiva, a partir das pistas semióticas que a imagem do presidente ativa na memória de seus "hipotéticos" interlocutores, na primeira parte da correlação (dita prótase), temos o 
enunciado "um amigo de verdade não é aquele que separa uma briga..." e, na segunda parte da correlação (dita apódose), temos o enunciado "mas sim, aquele que já chega dando voadora".

Assim como ocorre no discurso estruturado sob correlação "não $-\mathrm{x}$, mas sim $-\mathrm{y}$ " na figura 3, na figura 4, o EUc engendra, em seu projeto de fala, negar o discurso de uma voz geral acerca do tema amizade.

Dessa forma, o enunciado presente na prótase funciona como um primeiro argumento que se encarrega de marcar, sob a negação argumentativa, a tensão relacional sobre o tema amizade, o qual se torna objeto de troca entre as entidades que participam desse contrato comunicativo. $O$ enunciado presente na apódose cumpre a função de influenciar o posicionamento do TUi sob a roupagem de uma segunda voz geral. Essa segunda voz geral lança mão do operador argumentativo "mas" e seguido de ênfase afirmativa, busca ratificar seu posicionamento, o qual veicula um contra-argumento mais incisivo sobre o tema amizade.

Como vimos, ao se propor aqui um paralelo entre o texto e seu conteúdo semântico, pretende-se reafirmar que a estruturação do texto não é indiferente aos efeitos de sentido. Há processos que são mais bem estruturados pela coordenação, outros que admitem ser compreendidos como produto de uma coordenação ou de uma subordinação e outros ainda, que serão mais bem avaliados se vistos como resultantes de uma correlação. São operações que devem ser analisadas no nível da Enunciação, portanto, sob ação de sujeitos enunciadores.

Por fim, considerando os apontamentos das análises da figura 3 e da figura 4, podemos concluir que a estrutura "não $-\mathrm{x}$, mas sim $-\mathrm{y}$ " operaria, no nível do discurso, como uma estratégia semântico-argumentativa. Tal estratégia conduz a uma tensão relacional provocada pelo jogo polifônico entre duas vozes gerais. Nesse viés, a estrutura correlativa "não -x, mas sim -y", enquanto recurso semântico-argumentativo, funciona como um instrumento de manobra discursiva. Nesse processo, sua finalidade é dar ao interlocutor pistas das intenções comunicativas do locutor, para se chegar a uma conclusão, em uma determinada situação comunicativa.

\section{Considerações finais}

Com o objetivo de expor a importância da Correlação, como um recurso semânticoargumentativo, buscamos na Teoria Semiolinguística subsídios teóricos para a análise discursiva de enunciados estruturados sob a forma "não -x, mas sim -y" em textos do gênero meme. 
Portanto, com base no resultado da intersubjetividade encenada por sujeitos sociodiscursivos, concluímos que a estrutura correlativa "não -x, mas sim -y" equaliza duas vozes gerais, as quais manifestam aspectos psicológicos, sociais e históricos. Dessa forma, demonstramos que a correlação, para além de um recurso puramente sintático, é, antes, um recurso discursivo-argumentativo que entra em cena no jogo interacional da linguagem com o fito de provocar determinados efeitos de sentido.

Ademais, os textos do gênero meme demonstraram-nos ser um corpus bastante produtivo em que, devido a sua função comunicativa, podemos encontrar exemplos de textos que se estruturam sob a forma da correlação "não $-\mathrm{x}$, mas sim -y". Com isso, abrimos a possibilidade de se analisar a Correlação em outros gêneros textuais, que não sejam apenas aqueles de tipologia tipicamente argumentativa - como predominante nos gêneros artigo de opinião, editoriais, dissertações, teses, artigos científicos, dentre outros.

\section{Referências}

BAKHTIN, M. Estética da criação verbal. Trad. Maria Ermantina Galvão. São Paulo: Martins Fontes, 1997.

CAMARA JUNIOR, J. M. Dicionário de Linguística e Gramática. Petrópolis: Vozes, 1981.

CHARAUDEAU, P. Uma análise semiolinguística do texto e do discurso. In: PAULIUKONIS, M. A. L.; GAVAZZI, S. (Orgs.). Da língua ao discurso: reflexões para o ensino. Rio de Janeiro: Lucerna, 2007. p. 11-29.

CHARAUDEAU, P. Linguagem e discurso: modos de organização. Coordenação da equipe de tradução: Ângela Maria da Silva Corrêa e Ida Lúcia Machado. São Paulo: Contexto, 2008.

CHARAUDEAU, P. Dize-me qual é teu corpus, eu te direi qual é a tua problemática. In:

Revista Diadorim, Rio de Janeiro, v. 10, p. 1-23, dez. 2011. Disponível em:

https://revistas.ufrj.br/index.php/diadorim/article/view/3932/15637. Acesso em: 15 nov. 2019.

DUCROT, O. Polifonía y argumentación. Conferencias del Seminario Teoría de la Argumentación y Análisis del Discurso. Cali: Universidad del Valle, 1988.

DUCROT, O. Argumentação retórica e argumentação linguística. Letras de Hoje, Porto Alegre, v. 44, n. 1, p. 20-25, jan./mar., 2009.

KOCH, I. G. V. Argumentação e linguagem. São Paulo: Cortez, 2011.

MARI, H.; SILVEIRA, J. C. C. Sobre a importância dos gêneros discursivos. In:

MACHADO, I. L.; MELLO, R. de (Orgs.). Gêneros: Reflexões em Análise do Discurso.

Belo Horizonte: Núcleo de Análise do Discurso - FALE/UFMG, 2004. p. 59-74. 
MÓDOLO, M. Correlacionando orações na língua portuguesa. 2005. Disponível em: https://issuu.com/museulp/docs/correlacionando_ora_es_na_lingua. Acesso em 16 dez. 2019.

OITICICA, J. Teoria da Correlação. Rio de Janeiro: Organizações Simões, 1952.

PAULIUKONIS, M. A. L. Função argumentativa da correlação. In: PEREIRA, C. da C.; PEREIRA, P. R. D. (Orgs.). Miscelânea de estudos linguísticos, filológicos e literários in Memoriam Celso Cunha. Rio de Janeiro, Nova Fronteira, 1995. p. 337-347.

PAULIUKONIS, M. A. L. A estrutura correlativa como operador discursivo na articulação de cláusulas. SCRIPTA, Belo Horizonte, v. 5, n. 9, p. 119-125, 2001 a.

PAULIUKONIS, M. A. L. Processos de discursivização: da língua ao discurso caracterizações genéricas e específicas de um texto argumentativo. Revista Veredas, Juiz de Fora, v. 4, n. 2, p. 89-96, 2001 b.

RODRIGUES, V. V. Em foco a correlação. Revista Diadorim, Rio de Janeiro, v. 16, p. 122139, dez. 2014.

SOUZA, C. F. de. Memes: formações discursivas que ecoam no ciberespaço. Vértices, Campos dos Goytacazes, v. 15, n. 1, p. 127-148, jan./abr. 2013.

VOGT, C. Linguagem, Pragmática e Ideologia. São Paulo: Hucitec, 1980.

\section{Sobre os autores}

Daniele Cristina Campos (Orcid iD: https://orcid.org/0000-0002-6371-7944)

Mestranda no Programa de Pós-Graduação em Letras da Universidade Federal do Rio de Janeiro (UFRJ); especialista em Estudos Linguísticos e Literários pelo Instituto Federal do Rio de Janeiro (IFRJ); graduada em Letras - Português pela Universidade Federal Fluminense (UFF). Bolsista do CNPq (vigência: mar. 2019 - mar. 2020).

Maria Aparecida Lino Pauliukonis (Orcid iD: https://orcid.org/0000-0001-8057-9961) Doutora em Língua Portuguesa pela Universidade Federal do Rio de Janeiro (UFRJ); mestra em Literatura pela Universidade de São Paulo (USP); graduada em Letras - Português/Inglês pela Faculdade Estadual de Filosofia, Ciências e Letras de Franca - campus avançado da USP. Realizou pós-doutorado na Universidade Paris 13. É professora da Faculdade de Letras e do Programa de Pós-Graduação em Letras da UFRJ.

Recebido em agosto de 2020.

Aprovado em novembro de 2020. 